\title{
Azithromycin for Acute Exacerbations of Asthma
}

DOI:

10.1001/jamainternmed.2016.5664

\section{Document Version}

Final published version

Link to publication record in Manchester Research Explorer

\section{Citation for published version (APA):}

Johnston, S. L., Szigeti, M., Cross, M., Brightling, C., Chaudhuri, R., Harrison, T., Mansur, A., Robison, L., Sattar, Z., Jackson, D., Mallia, P., Wong, E., Corrigan, C., Higgins, B., Ind, P., Singh, D., Thomson, N. C., Ashby, D., Chauhan, A., \& AZALEA Trial Team (2016). Azithromycin for Acute Exacerbations of Asthma: The AZALEA Randomized Clinical Trial. JAMA Internal Medicine, 176(11), 1630-1637.

https://doi.org/10.1001/jamainternmed.2016.5664

\section{Published in:}

JAMA Internal Medicine

\section{Citing this paper}

Please note that where the full-text provided on Manchester Research Explorer is the Author Accepted Manuscript or Proof version this may differ from the final Published version. If citing, it is advised that you check and use the publisher's definitive version.

\section{General rights}

Copyright and moral rights for the publications made accessible in the Research Explorer are retained by the authors and/or other copyright owners and it is a condition of accessing publications that users recognise and abide by the legal requirements associated with these rights.

\section{Takedown policy}

If you believe that this document breaches copyright please refer to the University of Manchester's Takedown Procedures [http://man.ac.uk/04Y6Bo] or contact uml.scholarlycommunications@manchester.ac.uk providing relevant details, so we can investigate your claim.

\section{OPEN ACCESS}




\section{Azithromycin for Acute Exacerbations of Asthma The AZALEA Randomized Clinical Trial}

Sebastian L. Johnston, MBBS, PhD; Matyas Szigeti, MSc; Mary Cross, BA (Hons); Christopher Brightling, MBBS, PhD; Rekha Chaudhuri, MBBS, MD; Timothy Harrison, MBBS, PhD; Adel Mansur, MBBS, PhD; Laura Robison, BSc; Zahid Sattar, BSc, PhD; David Jackson, MBBS, PhD; Patrick Mallia, MBBS, PhD; Ernie Wong, MBBS, BSc; Christopher Corrigan, MA, PhD; Bernard Higgins, MBBS; Philip Ind, MB, BChir, PhD; Dave Singh, MB, BChir, MD; Neil C. Thomson, MBChB, MD; Deborah Ashby, PhD, CStat; Anoop Chauhan, MBBS, PhD; for the AZALEA Trial Team

IMPORTANCE Guidelines recommend against antibiotic use to treat asthma attacks. A study with telithromycin reported benefit, but adverse reactions limit its use.

OBJECTIVE To determine whether azithromycin added to standard care for asthma attacks in adults results in clinical benefit.

DESIGN, SETTING, AND PARTICIPANTS The Azithromycin Against Placebo in Exacerbations of Asthma (AZALEA) randomized, double-blind, placebo-controlled clinical trial, a United Kingdom-based multicenter study in adults requesting emergency care for acute asthma exacerbations, ran from September 2011 to April 2014. Adults with a history of asthma for more than 6 months were recruited within 48 hours of presentation to medical care with an acute deterioration in asthma control requiring a course of oral and/or systemic corticosteroids.

INTERVENTIONS Azithromycin 500 mg daily or matched placebo for 3 days.

MAIN OUTCOMES AND MEASURES The primary outcome was diary card symptom score 10 days after randomization, with a hypothesized treatment effect size of -0.3 . Secondary outcomes were diary card symptom score, quality-of-life questionnaires, and lung function changes, all between exacerbation and day 10 , and time to a $50 \%$ reduction in symptom score.

RESULTS Of 4582 patients screened at 31 centers, 199 of a planned 380 were randomized within 48 hours of presentation. The major reason for nonrecruitment was receipt of antibiotics (2044 [44.6\%] screened patients). Median time from presentation to drug administration was 22 hours (interquartile range, 14-28 hours). Exacerbation characteristics were well balanced across treatment arms and centers. The primary outcome asthma symptom scores were mean (SD), 4.14 (1.38) at exacerbation and 2.09 (1.71) at 10 days for the azithromycin group and 4.18 (1.48) and 2.20 (1.51) for the placebo group, respectively. Using multilevel modeling, there was no significant difference in symptom scores between azithromycin and placebo at day 10 (difference, $-0.166 ; 95 \% \mathrm{Cl},-0.670$ to 0.337 ), nor on any day between exacerbation and day 10 . No significant between-group differences were observed in quality-of-life questionnaires or lung function between exacerbation and day 10 , or in time to $50 \%$ reduction in symptom score.

CONCLUSIONS AND RELEVANCE In this randomized population, azithromycin treatment resulted in no statistically or clinically significant benefit. For each patient randomized, more than 10 were excluded because they had already received antibiotics.

TRIAL REGISTRATION clinicaltrials.gov Identifier: NCT01444469

JAMA Intern Med. 2016;176(11):1630-1637. doi:10.1001/jamainternmed.2016.5664

Published online September 19, 2016.

Invited Commentary pages 1637 and 1649

Related article page 1639

Supplemental content

CME Quiz at

jamanetworkcme.com and CME Questions 1732
Author Affiliations: Author affiliations are listed at the end of this article.

Group Information: The AZALEA Trial Team members are listed in Supplement 1.

Corresponding Author: Sebastian L. Johnston, MBBS, PhD, Airway Disease Infection Section, Nationa Heart and Lung Institute, Imperial College London, Norfolk PI, London W2 1PG, England (s.johnston @imperial.ac.uk). 
A sthma morbidity, mortality, and major health care costs result from acute attacks (exacerbations). ${ }^{1}$ The majority of patients with asthma report an exacerbation in the past year, with more than one-third of children and more than one-fourth of adults requiring consequent urgent medical care. ${ }^{2}$

Respiratory viral infections are a frequent cause of asthma exacerbations in children ${ }^{3,4}$ and adults. ${ }^{5-7}$ Atypical bacterial (Mycoplasma pneumoniae and Chlamydophila pneumoniae) infection and/or reactivation is also associated, with serologic positivity rates of $40 \%$ to $60 \%$ in some studies, ${ }^{8-12}$ indicating that viral and atypical bacterial infections may interact in increasing asthma exacerbation risk.

People with asthma have increased susceptibility to streptococcal infections, ${ }^{13-15}$ increased carriage of bacterial pathogens identified by culture ${ }^{16}$ and molecular techniques, ${ }^{17}$ and impaired interferon and type $1 \mathrm{~T}$ helper cell responses to bacterial polysaccharides. ${ }^{18,19}$ Viral infection impairs antibacterial innate immune responses ${ }^{2 \mathrm{O}}$ and increases bacterial adherence to bronchial epithelium. ${ }^{21}$ Thus, bacterial infections are more common and more severe in patients with asthma, viruses increase susceptibility to bacterial infection, and acute wheezing episodes in children younger than 3 years were associated with both bacterial and viral infection. ${ }^{22}$

Patients with asthma exacerbations treated with telithromycin had greater reductions in asthma symptoms, improvement in lung function, and faster recovery compared with placebo. ${ }^{12}$ However, toxic effects to the liver limit telithromycin treatment to life-threatening infections, and guidelines recommend that antibiotics should not be administered routinely in patients with asthma exacerbations. ${ }^{23,24}$

The Azithromycin Against Placebo in Exacerbations of Asthma (AZALEA) study investigated the effectiveness of azithromycin treatment when added to standard care for adult patients with asthma exacerbations, closely following the telithromycin study design, with the aim of providing confirmation or otherwise of those results.

Macrolide antibiotics might benefit asthma exacerbations through antimicrobial activity and/or anti-inflammatory properties ${ }^{25}$; and azithromycin, but not telithromycin, has been shown to have antiviral properties, ${ }^{26}$ augmenting production of interferons that are deficient in patients with asthma. ${ }^{19,27} \mathrm{~A}$ mechanistic and exploratory aim of AZALEA was to determine whether treatment benefited patients with these infections.

\section{Methods}

Study Design

This United Kingdom-based multicenter, double-blind, placebo-controlled study randomized eligible patients to azithromycin 500 mg daily or placebo for 3 days on day 1 (visit 1), with posttherapy assessments at visits on days 5 (visit 2) and 10 (visit 3) and for serum sampling at 6 weeks (visit 4) (see trial protocol in Supplement 2).

The main inclusion criteria were that participants be adults aged 18 to 55 years with any smoking history, aged 56 to 65 years with a less than 20 pack-year smoking history, or older

\section{Key Points}

Question Does addition of azithromycin to standard care improve outcomes in adults requesting acute medical care for asthma attacks?

Findings This randomized clinical trial found no statistically or clinically significant benefit in symptoms, lung function, or speed of recovery. For every 1 patient randomized, more than 10 had to be excluded because they had already received antibiotics.

Meaning Widespread use of antibiotics despite guideline recommendations limited interpretation of the results of this study.

than 65 years with a less than 5 pack-year smoking history, with a documented history of asthma for more than 6 months, and recruitment within 48 hours of presentation to medical care with an acute deterioration in asthma control (increased wheeze, dyspnea, and/or cough) necessitating a course of oral and/or systemic corticosteroids (based on clinical judgement by attending physicians) and a peak expiratory flow (PEF) or forced expiratory volume in 1 second $\left(\mathrm{FEV}_{1}\right)$ less than $80 \%$ predicted or patient's best at presentation, at recruitment, or in the time elapsed between presentation and recruitment.

The main exclusion criteria were use of oral and/or systemic antibiotics within 28 days of enrollment, need for intensive care, substantial lung disease other than asthma, longterm use of more than $20 \mathrm{mg}$ oral corticosteroid daily, known QT-interval prolongation, history of bradyarrhythmias and/or tachyarrhythmias or uncompensated heart failure, and patients taking drugs known to prolong the QT interval.

The primary outcome was diary card summary symptom score, with symptoms including wheezing, breathlessness, and coughing assessed at 10 days after randomization (as in the telithromycin study). ${ }^{12}$ Secondary outcomes included the acute Asthma Quality of Life Questionnaire (AQLQ), the mini AQLQ, $\mathrm{FEV}_{1}$, forced vital capacity (FVC), $\mathrm{FEV}_{1} / \mathrm{FVC}$, forced midexpiratory flow $\left(\mathrm{FEF}_{25 \%-75 \%}\right)$, forced expiratory flow at $50 \%$ expiration $\left(\mathrm{FEF}_{50 \%}\right), \mathrm{PEF}$, and time to $50 \%$ reduction in symptom score. Primary and secondary outcomes were assessed over the time course of the exacerbation to 10 days, and subgroup analyses were planned in relation to initial standard and/or atypical bacteriologic and virologic status.

Spontaneous or induced sputum samples were obtained where possible at exacerbation and sent for quantitative bacteria culture. A nasal mucus sample and nasal and throat swab samples were obtained where possible at exacerbation, and these and spontaneous or induced sputum samples were analyzed by means of viral and atypical bacterial polymerase chain reactions (PCRs) and acute and convalescent serum samples were sent for atypical bacterial serologic analysis.

The trial received approval from the National Research Ethics Committee, Bloomsbury, London, England, and all patients gave written informed consent. Additional methods are available in the eMethods in Supplement 1.

\section{Statistical Analyses}

The sample size calculations hypothesized a treatment mean (SD) effect size of $-0.3(0.783)$ based on the primary outcome 
Figure 1. Consolidated Standards of Reporting Trials Diagram of the Azithromycin for Acute Exacerbations of Asthma (AZALEA) Trial

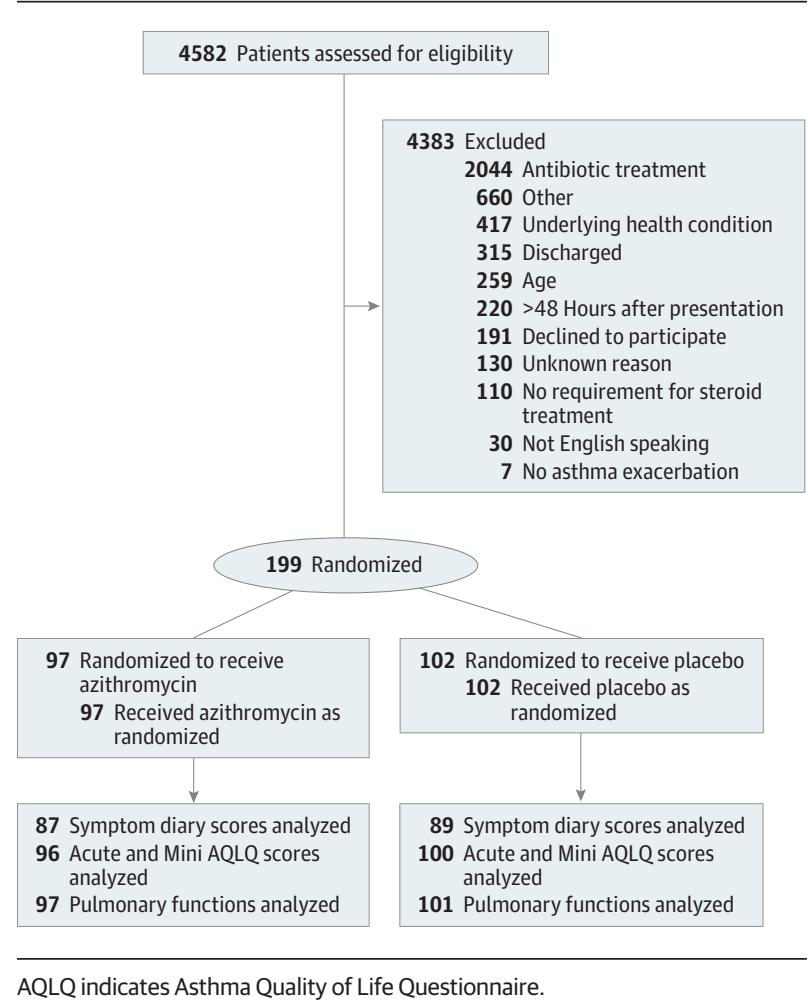

of the telithromycin study ${ }^{12}$ and used a significance level of $1 \%$ with $80 \%$ power, assuming a dropout rate of $15 \% .{ }^{12}$ We proposed to recruit 190 patients to each arm. To run the trial within the project funding 1-year timeline, we planned 10 centers, each recruiting roughly 38 patients.

All patients who returned at least 1 diary card and received study drug were included in the intention-to-treat analyses. Because the timing of greatest magnitude of any treatment effect was not known, multilevel modeling was used to calculate the estimated differences in primary and secondary outcomes between treatment groups for each day from randomization to day 10. A Cox model was used to calculate the hazard ratio for time to $50 \%$ reduction in symptom score. Details of the statistical model, model selection process, and treatment of missing data are in the eMethods in Supplement 1. All analyses were performed using Stata 13. A statistical analysis plan was prepared by the trial statistician prior to unblinding.

\section{Results}

\section{Recruitment Details and Clinical Characteristics}

Recruitment from 31 sites (30 secondary care hospitals, 1 primary care center) lasted 2.5 years, from October 12, 2011, to April 30, 2014. The recruitment period was longer than planned because of recruitment difficulties arising from the large numbers of patients excluded. A total of 4582 patients were screened, of whom 390 patients met eligibility criteria. A total of 199 were randomized, 97 to active treatment and 102 to pla- cebo (Figure 1). The major reason for nonrecruitment was already receiving antibiotics (2044 [44.6\%] screened patients).

Clinical characteristics of randomized patients are summarized in Table 1. Study participants' mean (SD) age was 39.9 (14.82) years (median [interquartile range] age, 38.4 [26.749.5] years), with $69.8 \%$ female. Underlying asthma severity, smoking status, exacerbation severity, and median time from presentation to trial drug administration are presented in Table 1. Pulmonary function at baseline (exacerbation, visit 1) is presented in Table 2 and includes mean (SD) PEF, 69.4\% (22.7\%) of predicted; $\mathrm{FEV}_{1}, 64.8 \%$ (21.4\%) of predicted; and $\mathrm{FEV}_{1} / \mathrm{FVC}, 69.2 \%$ (13.5\%). Baseline characteristics were well balanced across treatment arms and centers.

Of the 199 patients randomized, all attended visit 1 (randomization), 21 (10.6\%) missed visit 2, 28 (14.1\%) missed visit 3 , and 39 (19.6\%) missed visit 4; 159 (80\%) patients attended all follow-up visits. Missing visits and/or data were balanced between the treatment arms. Day 1 was defined as the day of administration of study drug.

\section{Primary Outcome Analysis}

Mean (SD) asthma symptom scores (from 0 = no symptoms to 6 = severe symptoms) were 4.14 (1.38) at baseline (exacerbation) and 2.09 (1.71) at day 10 for the azithromycin group and 4.18 (1.48) and 2.20 (1.51), respectively, for placebo. Using multilevel modeling, there was no statistically significant difference in symptom scores between groups at day 10 (difference, -0.166 ; 95\% CI, -0.670 to 0.337 ) (Figure 2 and eTable 3 in Supplement 1).

\section{Secondary Outcome Analyses}

Multilevel modeling revealed no significant between-group differences in symptom scores on any day between baseline and day 10 (Figure 2 and eTable 3 in Supplement 1). Significant between-group differences were seen in neither the acute AQLQ, the mini AQLQ (Figure 3A and B and eTables 7-10 in Supplement 1 ), nor in any measure of lung function (eTables 11 and 12 in Supplement 1) on any day from baseline to day 10, and there was no difference in time to $50 \%$ reduction in symptom score (hazard ratio, 1.03; 95\% CI, 0.71-1.49) (Figure 3C).

\section{Pathogen Detection Results}

One hundred five (52.8\%) patients provided sputum samples for bacterial culture, 191 (96.0\%) nasal and throat swabs and/or nasal mucus samples for virus and atypical bacterial PCR, and 158 (79.4\%) acute (IgM) and acute and convalescent (IgG, IgA) serum samples for atypical bacterial serologic analysis. A bacterial and/or atypical bacterial test positive result occurred in $21(10.6 \%)$ patients (9 [9.3\%] active, 12 [11.8\%] placebo). Nasal and/or throat swab and/or mucus and/or sputum virus PCRs had positive results in $36(18.1 \%)$ patients (16 [16.5\%] active, 20 [19.6\%] placebo).

\section{Subgroup Analyses}

There were no differences in the primary outcome asthma symptom score between treatment groups in patients with positive sputum bacterial culture results, atypical bacterial PCR and/or serologic analysis results, or virus PCR test 
results (including any bacteria and/or virus positive test result) (eTables 13-15 and eFigures 6-8 in Supplement 1), although patient numbers for these analyses were low.

\begin{tabular}{|c|c|c|}
\hline Characteristic & $\begin{array}{l}\text { Azithromycin } \\
(\mathrm{n}=97)\end{array}$ & $\begin{array}{l}\begin{array}{l}\text { Placebo } \\
(\mathrm{n}=102)\end{array} \\
\end{array}$ \\
\hline Age, median (IQR), y & $39.1(28.9-49.5)$ & $36.2(25.4-49.3)$ \\
\hline \multicolumn{3}{|l|}{ Sex, No. (\%) } \\
\hline Male & $33(34)$ & $27(26)$ \\
\hline Female & $64(66)$ & $75(74)$ \\
\hline \multicolumn{3}{|l|}{ Asthma severity $(n=198)$, No. $(\%)^{28}$} \\
\hline Step 1: mild intermittent asthma & $7(7)$ & $13(13)$ \\
\hline Step 2: regular preventer therapy & $30(31)$ & $26(26)$ \\
\hline Step 3: initial add-on therapy & $31(32)$ & $27(27)$ \\
\hline Step 4: persistent poor control & $22(23)$ & $22(22)$ \\
\hline $\begin{array}{l}\text { Step 5: continuous/frequent oral } \\
\text { steroids }\end{array}$ & $7(7)$ & $13(13)$ \\
\hline \multicolumn{3}{|l|}{ Smoking status, No. (\%) } \\
\hline Never & $60(62)$ & $61(60)$ \\
\hline Former & $26(27)$ & $19(19)$ \\
\hline Current & $11(11)$ & $21(21)$ \\
\hline $\begin{array}{l}\text { Smoking pack-years for current } \\
\text { or former smokers }(n=75) \text {, } \\
\text { median (IQR) [range] }\end{array}$ & $5(1-12)[0-20]$ & $5(2-12)[0-22]$ \\
\hline \multicolumn{3}{|l|}{$\begin{array}{l}\text { Asthma exacerbation }(n=198) \text {, } \\
\text { No. }(\%)\end{array}$} \\
\hline Mild exacerbation & $5(5)$ & $3(3)$ \\
\hline Moderate exacerbation & $26(27)$ & $35(35)$ \\
\hline Acute severe asthma & $61(63)$ & $56(55)$ \\
\hline Life-threatening asthma & $4(4)$ & $7(7)$ \\
\hline Near-fatal asthma & $1(1)$ & 0 \\
\hline $\begin{array}{l}\text { Time from presentation to receipt of } \\
\text { study drug }(n=192) \text {, median (IQR), } h\end{array}$ & $21(12-29)$ & $22(14-28)$ \\
\hline
\end{tabular}

Safety

Adverse events were infrequent (eTables 16-22 in Supplement 1), with more gastrointestinal adverse events in the azithromycin group compared with placebo (35 vs 24 events, respectively) (eTable 16 in Supplement 1). There was an increased frequency of cardiac adverse events ( 4 vs 2 , respectively) in the azithromycin group compared with placebo and a reduced frequency of respiratory, thoracic, and mediastinal (63 of 64 respiratory) adverse events (27 vs 37, respectively) (eTables 16 and 20 in Supplement 1), suggesting that antibiotic therapy possibly reduced respiratory adverse events in this population.

\section{Discussion}

In the patients with asthma exacerbations randomized to treatment or placebo in this study, the addition of azithromycin to

Figure 2. Primary Outcome Symptom Diary Scores From Randomization to Day 10

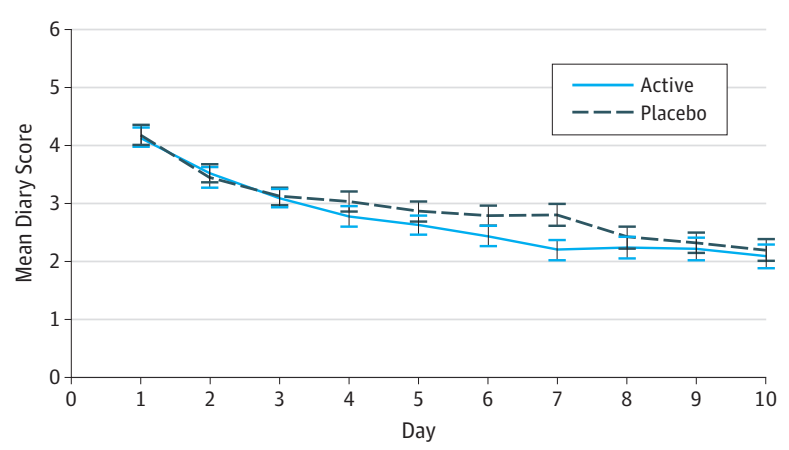

Error bars indicate standard error.

Table 2. Baseline (Exacerbation) Pulmonary Function by Treatment Arm

\begin{tabular}{|c|c|c|c|c|c|}
\hline \multirow[b]{2}{*}{ Pulmonary Function } & \multirow{2}{*}{$\begin{array}{l}\text { Patients, } \\
\text { No. }\end{array}$} & \multirow[b]{2}{*}{ Mean (SD) } & \multicolumn{3}{|c|}{ Percentile } \\
\hline & & & 25th & 50th & 75th \\
\hline \multicolumn{6}{|l|}{ Azithromycin } \\
\hline $\mathrm{FEV}_{1}, \mathrm{~L}$ & 95 & $1.9(0.7)$ & 1.4 & 1.8 & 2.5 \\
\hline $\mathrm{FEV}_{1 \%}$ predicted, $\%$ & 93 & $63.2(21.8)$ & 48 & 63 & 79 \\
\hline FVC, L & 96 & $2.8(1.0)$ & 2.0 & 2.7 & 3.5 \\
\hline $\mathrm{FEV}_{1} / \mathrm{FVC}$ ratio & 94 & $69.7(13.3)$ & 62.0 & 70.0 & 79.0 \\
\hline $\mathrm{FEF}_{25 \%-75 \%}, \mathrm{~L} / \mathrm{s}$ & 80 & $1.6(0.9)$ & 0.9 & 1.4 & 2.1 \\
\hline $\mathrm{FEF}_{50 \%}, \mathrm{~L} / \mathrm{s}$ & 76 & $1.9(1.1)$ & 1.1 & 1.7 & 2.6 \\
\hline $\mathrm{PEF}, \mathrm{L} / \mathrm{min}$ & 93 & $290(104)$ & 215 & 283 & 348 \\
\hline PEF \% predicted, \% & 92 & $65.7(23.4)$ & 47.0 & 67.0 & 79.0 \\
\hline \multicolumn{6}{|l|}{ Placebo } \\
\hline $\mathrm{FEV}_{1}, \mathrm{~L}$ & 96 & $2.1(0.8)$ & 1.5 & 2.0 & 2.6 \\
\hline $\mathrm{FEV}_{1 \%}$ predicted, $\%$ & 96 & $66.3(21.0)$ & 52.5 & 64.0 & 84.0 \\
\hline FVC, L & 96 & $3.1(1.0)$ & 2.4 & 3.0 & 3.6 \\
\hline $\mathrm{FEV}_{1} / \mathrm{FVC}$ ratio & 96 & $68.8(13.7)$ & 58.0 & 69.0 & 79.5 \\
\hline $\mathrm{FEF}_{25 \%-75 \%}, \mathrm{~L} / \mathrm{s}$ & 87 & $1.7(1.1)$ & 0.9 & 1.4 & 2.4 \\
\hline $\mathrm{FEF}_{50 \%}, \mathrm{~L} / \mathrm{s}$ & 84 & $2.0(1.3)$ & 1.1 & 1.7 & 2.8 \\
\hline $\mathrm{PEF}, \mathrm{L} / \mathrm{min}$ & 96 & $323(98)$ & 248 & 341 & 390 \\
\hline PEF \% predicted, \% & 95 & $73.0(21.5)$ & 56.0 & 75.0 & 90.0 \\
\hline
\end{tabular}

Abbreviations: $\mathrm{FEF}_{25 \%-75 \% \text {, forced }}$ mid-expiratory flow; $\mathrm{FEF}_{50 \%}$, forced expiratory flow at $50 \%$ expiration; $\mathrm{FEV}_{1}$, forced expiratory volume in 1 second; FEV $/$ FVC, ratio of forced expiratory volume in 1 second to forced vital capacity; FVC, forced vital capacity; PEF, peak expiratory flow. 
Figure 3. Secondary Outcome Acute and Mini Asthma Quality of Life Questionnaire (AQLQ) Scores From Randomization to Day 10 and Time to $50 \%$ Reduction in Symptom Diary Score
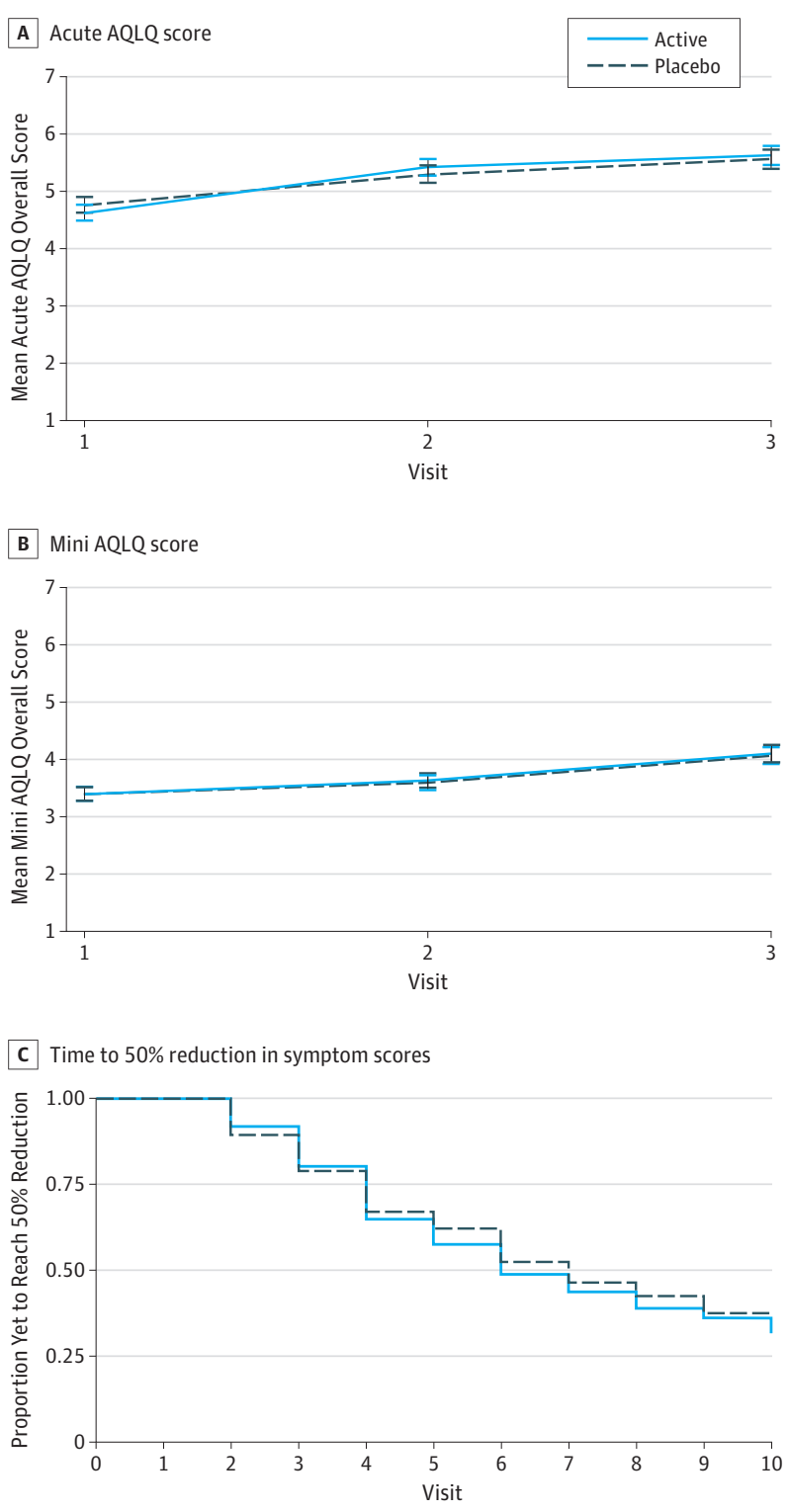

A and B, Acute and Mini AQLQ mean scores by visits for each treatment arm. Error bars indicate standard error. C, Kaplan-Meier curves of time to a 50\% reduction in symptom diary score for each treatment arm (truncated at 10 days).

standard medical care resulted in no statistically or clinically significant therapeutic benefit. The findings were consistently negative across 3 different symptom and quality-of-life scores, including 1 previously reporting statistically and clinically significant benefit with telithromycin treatment. ${ }^{12}$ The findings were also negative for all measures of lung function, including $\mathrm{FEV}_{1}$, which was significantly improved in the previous study, ${ }^{12}$ and for time to a $50 \%$ reduction in asthma symptoms, which was significantly improved in the previous study. ${ }^{12}$

Recruitment proved challenging; initially there were 10 centers, each aiming to recruit 38 participants over 1 winter sea- son, to recruit the planned 380 patients. Our power calculation deliberately mandated large patient numbers to provide statistically robust data to settle the important clinical question regarding antibiotic efficacy in this setting (for comparison, the telithromycin study randomized 270 patients)..$^{12} \mathrm{We}$ also desired larger patient numbers to enhance subgroup analyses aimed at potentially important mechanistic questions. Once recruitment obstacles became clear with such widespread antibiotic use, a total of 31 centers were enrolled, inclusion criteria were relaxed to change eligibility criteria from less than 24 to less than 48 hours from time of presentation, to include older participants with low smoking histories, and recruitment was extended to 2 years and 7 months. However, despite all these efforts, only 199 participants were recruited by medication expiry and funding end dates and the study was terminated despite not reaching its recruitment target. The study was therefore underpowered and a difference of 0.3 in mean symptom score between treatment arms at 10 days cannot be excluded.

The different outcomes of the present and previous studies, ${ }^{12}$ which used closely related therapies in similar study designs, require interpretation and/or explanation. The antibiotics studied are different, albeit related. Both drugs were used at their standard recommended doses and durations of therapy. The shorter duration of treatment with azithromycin (3 days vs 10 days with telithromycin) is unlikely to explain the difference in outcome because azithromycin has a long tissue halflife and is likely to have remained at therapeutic doses in the lung for approximately 10 days. ${ }^{29}$ Azithromycin but not telithromycin has antiviral activity, ${ }^{26}$ so this is an unlikely explanation. In terms of antibacterial activity against relevant respiratory bacteria, telithromycin is reportedly more active than azithromycin against Streptococcus pneumoniae but has similar activity against both Moraxella catarrhalis and Haemophilus influenzae. ${ }^{30-32}$ Because the present study only detected 3 $S$ pneumoniae, $1 \mathrm{M}$ catarrhalis, and no $H$ influenzae infections in the active treatment arm, differences in activity against these organisms seem unlikely to explain the differing outcomes. In terms of anti-inflammatory activities, both drugs reportedly have similar activities when compared. ${ }^{25}$

A remarkable finding of this study was the number of patients (2044) excluded because they were already receiving antibiotic therapy for their asthma exacerbation despite treatment guidelines recommending that such therapy not be routinely given. ${ }^{23,24}$ For each patient randomized, more than 10 were excluded for this reason. This important finding has obvious and worrying implications regarding antibiotic stewardship ${ }^{33}$; in addition, such high antibiotic use rates may also have directly influenced the study outcome because it is possible that patients who might potentially have benefitted from antibiotic therapy for their asthma exacerbation (through having sputum production, sputum purulence, fever) were excluded from the study through already having received them. The population remaining to be randomized could theoretically have been selected against for antibiotic responsiveness, through having no clinical indication that antibiotic therapy might be of benefit. This is possible because patients being screened had often been seen by their primary care practitioner, by emergency department medical staff, and by a 
member of the on-call respiratory and/or medical team, so in many instances 3 independent physicians and/or teams had assessed them, including their suitability for antibiotic therapy. It is likely therefore that those not prescribed antibiotics were negatively selected against, for suitability for antibiotics. This interpretation is supported by the low bacterial and/or atypical bacterial positivity rate found in this study: only $9.3 \%$ of azithromycin-treated participants.

It is also possible that the population randomized were in other ways not representative of the larger population screened because more than 2000 other patients were excluded from the study for other reasons (Figure 1). The telithromycin study did not report numbers of patients screened, ${ }^{12}$ so it is not possible to determine to what extent these caveats may also have applied to that study.

A further difference is that all patients randomized to this study were required to be prescribed oral and/or systemic corticosteroid treatment, whereas in the telithromycin study only $34.1 \%$ of patients randomized to active treatment required corticosteroid therapy. ${ }^{12}$ Requirement for corticosteroid treatment in this study was designed to reduce the number of milder exacerbations studied. However, if our study included largely non-bacterially infected participants, this could have resulted in us studying possible anti-inflammatory effects of azithromycin, in the face of the powerful anti-inflammatory effects of corticosteroids, with predictably negative results.

The clinical characteristics of the patients in our study compared with those in the telithromycin study were similar in terms of mean age (39.9 years in our study vs 39.5 in the telithromycin study), sex (30.2\% male vs $32 \%)$, smoking status (mean of 3.44 vs 2.15 pack-years), exacerbation symptom score severity (4.16 vs 2.9), and lung function at exacerbation (PEF, $69.4 \%$ vs $55.2 \%$ of predicted; $\mathrm{FEV}_{1}, 64.8 \%$ vs $67.2 \%$ of predicted; $\mathrm{FEV}_{1} / \mathrm{FVC}, 69.2 \%$ vs $\left.72 \%\right) .{ }^{12}$ Differences in clinical characteristics do not seem a likely explanation for the difference in outcome of the 2 studies.

The studies differed strikingly in one regard: $61 \%$ of telithromycin-treated but only $5.2 \%$ of azithromycin-treated patients had a positive test result for current atypical bacterial infection. ${ }^{12}$ Both studies used similar sampling and detection methods, although the laboratories performing the analyses differed (GR Micro London, England, for telithromycin; S.L.J.'s laboratory for this study). Detection rates by PCR were low in both studies ( 3 positive in the telithromycin study and 0 positive in this study). In contrast, serological positive results differed markedly: the telithromycin study positive results were almost all $C$ pneumoniae IgM positives, while in our study only 1 sample was IgM positive for this organism. Both studies used the same assay
(Medac C pneumoniae IgM sandwich enzyme-linked immunosorbent assay, Medac) so the discrepancy between the results of this assay is difficult to explain. This major difference in frequency of $C$ pneumoniae IgM positivity may have contributed to the difference in clinical outcomes between the 2 studies.

Sputum culture for standard bacteria was not performed in the telithromycin study. ${ }^{12}$ In the present study, 105 (52.8\%) participants provided sputum samples for bacterial culture and positivity was observed in $6.0 \%$ (4.1\% active, $7.8 \%$ placebo). These results, together with the negative outcomes in relation to therapy, suggest that the role of standard bacterial infection in the population studied was unlikely to be important.

Interpretation of the outcome of this study must be considered in the light of prior knowledge that noninfectious agents can also trigger exacerbations, and of other randomized placebo-controlled studies investigating the effects of similar therapies in acute wheezing episodes. In addition to the telithromycin study reporting positive outcomes in asthma exacerbations in adults, ${ }^{12}$ azithromycin treatment during bronchiolitis in infancy was reported to reduce nasal lavage interleukin 8 levels, the occurrence of postbronchiolitic wheezing, ${ }^{34}$ and the duration of acute episodes of asthma-like symptoms in 1- to 3-year-old children. ${ }^{35}$ Furthermore, in 1- to 6-year-old children with histories of recurrent severe lower respiratory tract infections (LRTIs), azithromycin treatment early during an apparent respiratory tract infection reduced the likelihood of severe LRTI. ${ }^{36}$ Finally, low-dose azithromycin prophylaxis for 6 months in participants with exacerbationprone severe asthma did not reduce the primary outcome (rate of severe exacerbations and LRTIs necessitating treatment with antibiotics); however, in a predefined subgroup analysis according to inflammatory phenotype, azithromycin treatment benefitted participants with noneosinophilic severe asthma. ${ }^{37}$ We therefore carried out a similar post hoc analysis but found no evidence of benefit in this subgroup (eResults in Supplement 1). Thus, further study of azithromycin treatment in acute exacerbations of asthma in adults and children in settings of low rates of antibiotic use and stratifying on blood and/or sputum cell counts seems justified.

\section{Conclusions}

In the patients randomized to treatment or placebo in this study, addition of azithromycin to standard medical care resulted in no statistically significant or clinically important benefit. However, for each patient randomized, more than 10 were excluded because they had already received antibiotics.

\section{ARTICLE INFORMATION}

Accepted for Publication: July 15, 2016.

Published Online: September 19, 2016 doi:10.1001/jamainternmed.2016.5664

Author Affiliations: National Heart and Lung Institute, Imperial College London, London, England (Johnston, Jackson, Mallia, Wong, Ind); Imperial Clinical Trials Unit, School of Public Health, Imperial College London, London, England (Szigeti,
Cross, Robison, Sattar, Ashby); Institute for Lung Health, University of Leicester, Leicester, England (Brightling); Institute of Infection Immunity and Inflammation, University of Glasgow, Glasgow, Scotland (Chaudhuri, Thomson); Respiratory Medicine, NHS Greater Glasgow and Clyde, Glasgow, Scotland (Chaudhuri); Nottingham Respiratory Research Unit, University of Nottingham, Nottingham, England (Harrison); Respiratory Medicine, Heart of England Foundation
Trust, Birmingham, England (Mansur); Severe and Brittle Asthma Unit, University of Birmingham, Birmingham, England (Mansur); Respiratory Medicine and Allergy, King's College London School of Medicine, London, England (Corrigan); Department of Asthma, Allergy and Respiratory Science, Guy's and St. Thomas' NHS Foundation Trust, London, England (Corrigan); Respiratory Medicine, Newcastle University, Newcastle, England (Higgins); Respiratory Medicine, Imperial 
College Healthcare NHS Trust, London, England (Ind); Centre for Respiratory Medicine and Allergy, Medicines Evaluation Unit, University of Manchester and University Hospital of South Manchester NHS Foundation Trust, Manchester, England (Singh); Respiratory Medicine, Portsmouth Hospitals NHS Trust, Portsmouth, England (Chauhan).

Author Contributions: Drs Johnston and Ashby had full access to all of the data in the study and take responsibility for the integrity of the data and the accuracy of the data analysis.

Study concept and design: Johnston, Cross, Brightling, Chaudhuri, Harrison, Mansur, Robison, Higgins, Ind, Singh, Thomson, Ashby, Chauhan. Acquisition, analysis, or interpretation of data: Johnston, Szigeti, Cross, Brightling, Chaudhuri, Harrison, Mansur, Robison, Sattar, Jackson, Mallia, Wong, Corrigan, Higgins, Singh, Thomson, Ashby, Chauhan.

Drafting of the manuscript: Johnston, Szigeti, Cross, Mansur, Robison, Jackson, Wong, Corrigan. Critical revision of the manuscript for important intellectual content: Johnston, Szigeti, Brightling, Chaudhuri, Harrison, Mansur, Robison, Sattar, Mallia, Wong, Corrigan, Higgins, Ind, Singh, Thomson, Ashby, Chauhan. Statistical analysis: Johnston, Szigeti, Sattar, Ashby. Obtained funding: Johnston, Cross, Brightling Mansur, Robison, Sattar, Thomson, Ashby. Administrative, technical, or material support Johnston, Cross, Brightling, Robison, Sattar, Jackson, Mallia, Corrigan, Ind.

Study supervision: Johnston, Brightling, Chaudhuri, Harrison, Robison, Wong, Ind, Singh, Thomson, Ashby, Chauhan.

Conflict of Interest Disclosures: Dr Johnston reports institutional funding for a clinical trial, research grant, and/or consultant compensation from AstraZeneca, Boehringer Ingelheim, Centocor, Chiesi, GlaxoSmithKline, Merck, Novartis, Roche/ Genentech, Sanofi Pasteur, and Synairgen; shareholding in Synairgen; 9 licensed patents and 1 patent pending. Dr Brightling reports grants and consultancy paid to institution from GlaxoSmithKline, AstraZeneca, Boehringer Ingelheim, Novartis, Chiesi, and Roche/Genentech. Dr Chaudhuri reports grants and personal fees for attendance at scientific conferences and advisory board meetings from Novartis Pharmaceuticals, AstraZeneca, Teva, and GlaxoSmithKline. Dr Corrigan reports grants and personal fees for attendance at scientific conferences and payments for lectures from Allergy Therapeutics; grants and personal fees for research collaborations and consultancy not connected with the present research from Novartis; grants for attendance at scientific conferences from Stallergenes, Boehringer Ingelheim, and Diagenics; and personal fees for speaking at conferences from AstraZeneca. Dr Higgins reports being a multicenter study, local principal investigator for studies funded by Novartis and Roche. Dr Singh reports grants and personal fees from Almirall, AstraZeneca, Boehringher Ingleheim, Chiesi, GlaxoSmithKline, Glenmark, Johnson and Johnson, Merck, NAPP, Novartis, Pfizer, Takeda, Teva, Therevance, and Verona and personal fees from Genentech and Skyepharma. No other disclosures are reported.

Funding/Support: This study was funded by the Efficacy and Mechanisms Evaluation programme of the Medical Research Council (MRC), in partnership with the National Institute for Health Research (NIHR) (Funders Reference No. 10/60/27). The trial was supported by the NIHR Comprehensive Biomedical Research Centre based at Imperial College Healthcare NHS Trust and Imperial College London. Dr Johnston is an NIHR senior investigator and was supported by European Research Council FP7 Advanced Grant 233015, a Chair from Asthma UK (CH11SJ), and MRC Centre grant G1000758.

Role of the Funder/Sponsor: The funders had no role in the design and conduct of the study: collection, management, analysis, and interpretation of the data; preparation, review, or approval of the manuscript; and decision to submit the manuscript for publication.

Disclaimer: The views expressed in this article are those of the authors and not necessarily those of the National Health Service, the NIHR, or the Department of Health.

Additional Contributions: We would like to thank the patients who took part in the trial; Josephine Marange, Research Nurse, Birmingham Heartlands Hospital, UK, for assistance with patient recruitment; Elena Kulinskaya, PhD, Senior Statistician, Imperial College, London, for help with the power calculations; and the independent members of the Trial Steering Committee and Data Monitoring and Ethics Committee (membership listed in Supplement 1). No compensation was received beyond their salary for their contribution.

\section{REFERENCES}

1. Weiss KB, Sullivan SD. The health economics of asthma and rhinitis. I. assessing the economic impact. J Allergy Clin Immunol. 2001;107(1):3-8.

2. Rabe KF, Vermeire PA, Soriano JB, Maier WC Clinical management of asthma in 1999: the Asthma Insights and Reality in Europe (AIRE) study. Eur Respir J. 2000;16(5):802-807.

3. Johnston SL, Pattemore PK, Sanderson G, et al Community study of role of viral infections in exacerbations of asthma in 9-11 year old children. BMJ. 1995;310(6989):1225-1229.

4. Chauhan $\mathrm{AJ}$, Inskip $\mathrm{HM}$, Linaker $\mathrm{CH}$, et al. Personal exposure to nitrogen dioxide $\left(\mathrm{NO}_{2}\right)$ and the severity of virus-induced asthma in children. Lancet. 2003;361(9373):1939-1944.

5. Johnston SL, Pattemore PK, Sanderson G, et al The relationship between upper respiratory infections and hospital admissions for asthma: a time-trend analysis. Am J Respir Crit Care Med. 1996;154(3, pt 1):654-660.

6. Wark PA, Johnston SL, Moric I, Simpson JL, Hensley MJ, Gibson PG. Neutrophil degranulation and cell lysis is associated with clinical severity in virus-induced asthma. Eur Respir J. 2002;19(1):68-75.

7. Grissell TV, Powell H, Shafren DR, et al. Interleukin-10 gene expression in acute virus-induced asthma. Am J Respir Crit Care Med. 2005;172(4):433-439.

8. Wark PA, Johnston SL, Simpson JL, Hensley MJ, Gibson PG. Chlamydia pneumoniae immunoglobulin A reactivation and airway inflammation in acute asthma. Eur Respir J. 2002;20(4):834-840.

9. Esposito S, Blasi F, Arosio C, et al. Importance of acute Mycoplasma pneumoniae and Chlamydia pneumoniae infections in children with wheezing. Eur Respir J. 2000;16(6):1142-1146.
10. Cunningham $A F$, Johnston $S L$, Julious $S A$, Lampe FC, Ward ME. Chronic Chlamydia pneumoniae infection and asthma exacerbations in children. Eur Respir J. 1998;11(2):345-349.

11. Johnston SL, Martin RJ. Chlamydophila pneumoniae and Mycoplasma pneumoniae: a role in asthma pathogenesis? Am J Respir Crit Care Med. 2005;172(9):1078-1089.

12. Johnston SL, Blasi F, Black PN, Martin RJ, Farrell DJ, Nieman RB; TELICAST Investigators. The effect of telithromycin in acute exacerbations of asthma. N Engl J Med. 2006;354(15):1589-1600.

13. Talbot TR, Hartert TV, Mitchel E, et al. Asthma as a risk factor for invasive pneumococcal disease. N Engl J Med. 2005;352(20):2082-2090.

14. Klemets $P$, Lyytikäinen $O$, Ruutu $P$, et al. Risk of invasive pneumococcal infections among working age adults with asthma. Thorax. 2010;65(8):698-702. 15. Pilishvili T, Zell ER, Farley MM, et al. Risk factors for invasive pneumococcal disease in children in the era of conjugate vaccine use. Pediatrics. 2010;126 (1):e9-e17.

16. Jounio $U$, Juvonen $R$, Bloigu $A$, et al. Pneumococcal carriage is more common in asthmatic than in non-asthmatic young men. Clin Respir J. 2010;4(4):222-229.

17. Hilty M, Burke C, Pedro H, et al. Disordered microbial communities in asthmatic airways. PLOS One. 2010;5(1):e8578.

18. Message SD, Laza-Stanca V, Mallia P, et al. Rhinovirus-induced lower respiratory illness is increased in asthma and related to virus load and Th1/2 cytokine and IL-10 production. Proc Natl Acad SciU S A. 2008;105(36):13562-13567.

19. Contoli M, Message SD, Laza-Stanca V, et al. Role of deficient type III interferon- $\lambda$ production in asthma exacerbations. Nat Med. 2006;12(9):1023-1026.

20. Oliver BG, Lim S, Wark P, et al. Rhinovirus exposure impairs immune responses to bacterial products in human alveolar macrophages. Thorax. 2008;63(6):519-525.

21. Avadhanula V, Rodriguez CA, Devincenzo JP, et al. Respiratory viruses augment the adhesion of bacterial pathogens to respiratory epithelium in a viral species- and cell type-dependent manner. J Virol. 2006;80(4):1629-1636.

22. Bisgaard H, Hermansen MN, Bønnelykke $K$, et al. Association of bacteria and viruses with wheezy episodes in young children: prospective birth cohort study. BMJ. 2010;341:c4978.

23. British Thoracic Society; Scottish Intercollegiate Guidelines Network. British guideline on the management of asthma. Thorax. 2008;63(suppl 4): iv1-iv121.

24. Global Initiative for Asthma. Global Strategy for Asthma Management and Prevention (2015

Update). http://ginasthma.org/wp-content/uploads /2016/01/GINA_Report_2015_Aug11-1.pdf. Accessed July 1, 2016

25. Kobayashi Y, Wada H, Rossios C, et al. A novel macrolide solithromycin exerts superior anti-inflammatory effect via NF-kB inhibition. J Pharmacol Exp Ther. 2013;345(1):76-84.

26. Gielen V, Johnston SL, Edwards MR. Azithromycin induces anti-viral responses in bronchial epithelial cells. Eur Respir J. 2010;36(3): 646-654 
27. Wark PA, Johnston SL, Bucchieri F, et al Asthmatic bronchial epithelial cells have a deficient innate immune response to infection with rhinovirus. J Exp Med. 2005;201(6):937-947.

28. British Thoracic Society; Scottish Intercollegiate Guidelines Network. British guideline on the management of asthma. Thorax. 2014;69(suppl 1):1-192.

29. Zeitlinger M, Wagner CC, Heinisch B. Ketolides-the modern relatives of macrolides: the pharmacokinetic perspective. Clin Pharmacokinet. 2009;48(1):23-38.

30. Walsh F, Carnegy F, Willcock J, Amyes S. Comparative in vitro activity of telithromycin against macrolide-resistant and -susceptible Streptococcus pneumoniae, Moraxella catarrhalis and Haemophilus influenzae. J Antimicrob Chemother. 2004;53(5):793-796.

31. Kosowska K, Credito K, Pankuch GA, et al. Activities of two novel macrolides, GW 773546 and
GW 708408, compared with those of telithromycin, erythromycin, azithromycin, and clarithromycin against Haemophilus influenzae. Antimicrob Agents Chemother. 2004;48(11):4113-4119.

32. De Vecchi E, Nicola L, Larosa M, Drago L. In vitro activity of telithromycin against Haemophilus influenzae at epithelial lining fluid concentrations. BMC Microbiol. 2008;8:23.

33. Leung E, Weil DE, Raviglione M, Nakatani $H$; World Health Organization World Health Day Antimicrobial Resistance Technical Working Group. The WHO policy package to combat antimicrobial resistance. Bull World Health Organ. 2011;89(5): 390-392.

34. Beigelman $A$, Isaacson-Schmid M, Sajol G, et al. Randomized trial to evaluate azithromycin's effects on serum and upper airway IL-8 levels and recurrent wheezing in infants with respiratory syncytial virus bronchiolitis. J Allergy Clin Immunol. 2015;135(5):1171-1178.e1.
35. Stokholm J, Chawes BL, Vissing NH, et al. Azithromycin for episodes with asthma-like symptoms in young children aged $1-3$ years: a randomised, double-blind, placebo-controlled trial. Lancet Respir Med. 2016;4(1):19-26.

36. Bacharier LB, Guilbert TW, Mauger DT, et al; National Heart, Lung, and Blood Institute's AsthmaNet. Early administration of azithromycin and prevention of severe lower respiratory tract illnesses in preschool children with a history of such illnesses: a randomized clinical trial. JAMA. 2015; 314(19):2034-2044.

37. Brusselle GG, Vanderstichele $C$, Jordens $P$, et al. Azithromycin for prevention of exacerbations in severe asthma (AZISAST): a multicentre randomised double-blind placebo-controlled trial. Thorax. 2013; 68(4):322-329.

\section{AZALEA Trial Highlights Antibiotic Overuse in Acute Asthma Attacks}

Guy G. Brusselle, MD, PhD; Eva Van Braeckel, MD, PhD

Asthma affects more than 300 million people worldwide, causing variable symptoms of cough, chest tightness, and exertional or nocturnal dyspnea due to chronic inflammation of the lower airways and bronchial hyperresponsiveness. Acute episodes of worsening respiratory symptoms, called acute exacerbations or asthma attacks, can be life-threatening, and in-

$\leftarrow$ duce important costs, encomRelated article page 1630 passing both direct health care expenses and indirect costs due to absence from work or school. For many decades, asthma attacks have been treated with inhaled short-acting bronchodilators and systemic corticosteroids. There is thus a need for novel therapies which-as add-on treatment to systemic corticosteroidscould hasten clinical and functional recovery in patients experiencing an asthma attack and prevent complications.

In this issue of JAMA Internal Medicine, Johnston et $\mathrm{al}^{1}$ report the results of the Azithromycin Against Placebo for Acute Exacerbations of Asthma (AZALEA) trial. In this multicenter, randomized, double-blind, placebo-controlled study in the United Kingdom, they investigated the macrolide azithromycin as a supplement to standard treatment in adult patients presenting to emergency departments (EDs) with an acute asthma exacerbation. Patients were mainly recruited from secondary care hospitals and needed to be enrolled within 48 hours of initial presentation to medical care. Importantly, all patients received a course of oral or systemic corticosteroids. A total of 199 asthma patients (mean age, 40 years; $70 \%$ female) were randomized to azithromycin $500 \mathrm{mg}$ daily for 3 days or matching placebo. The primary outcome, that is, diary card asthma symptom score 10 days after randomization, was not different between the azithromycin and placebo groups. Likewise, there were no significant between-group differences in secondary outcomes such as quality-of-life questionnaires, lung function measurements during the exacerbation, or time to a $50 \%$ reduction in asthma symptoms. Therefore, addition of azithromycin to standard medical care for acute asthma exacerbations did not result in a statistically or clinically significant benefit. Adverse events were infrequent in both treatment groups, with more gastrointestinal adverse events in the azithromycin group compared with placebo. No data are provided on secondary ED visits or hospital (re-)admissions.

In contrast, the Telithromycin, Chlamydophila, and Asthma (TELICAST) study has demonstrated clinical benefit of treatment with telithromycin (800 mg daily for 10 days) vs placebo in acute asthma exacerbations. ${ }^{2}$ However, severe adverse reactions including liver toxicity limit the use of telithromycin in clinical practice. Why did the AZALEA trial have negative results, whereas the TELICAST study seemed to have positive results? First, there is a crucial difference in trial design: all patients randomized in the AZALEA trial were required to receive systemic corticosteroid treatment, whereas only $34 \%$ of randomized patients received corticosteroids in the TELICAST study. Because the beneficial effects of macrolides might be partially attributed to their anti-inflammatory properties, it is difficult to demonstrate benefit on top of the powerful anti-inflammatory effects of systemic corticosteroids, leading to predictably negative results in the AZALEA study as opposed to the TELICAST study. Second, in the AZALEA study only $5 \%$ of the azithromycin-treated patients tested positive for current infection with Chlamydophila pneumoniae or Mycoplasma pneumoniae, whereas in the TELICAST study $60 \%$ of telithromycin-treated patients had a positive IgM test result for one of these atypical organisms. Because both 